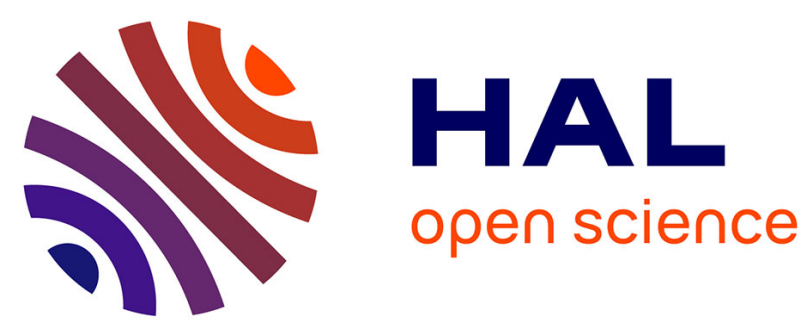

\title{
Fluropyrimidine single agent or doublet chemotherapy as second line treatment in advanced biliary tract cancer
}

Cindy Neuzillet, Andrea Casadei-gardini, Bertrand Brieau, Caterina Vivaldi, Giovanni Brandi, David Tougeron, Roberto Filippi, Angélique Vienot, Nicola Silvestris, Anne-laure Pointet, et al.

\section{To cite this version:}

Cindy Neuzillet, Andrea Casadei-gardini, Bertrand Brieau, Caterina Vivaldi, Giovanni Brandi, et al.. Fluropyrimidine single agent or doublet chemotherapy as second line treatment in advanced biliary tract cancer. International Journal of Cancer, 2020, 147 (11), pp.3177-3188. 10.1002/ijc.33146 . hal-02929354

\section{HAL Id: hal-02929354 https://hal-univ-rennes1.archives-ouvertes.fr/hal-02929354}

Submitted on 10 Sep 2020

HAL is a multi-disciplinary open access archive for the deposit and dissemination of scientific research documents, whether they are published or not. The documents may come from teaching and research institutions in France or abroad, or from public or private research centers.
L'archive ouverte pluridisciplinaire HAL, est destinée au dépôt et à la diffusion de documents scientifiques de niveau recherche, publiés ou non, émanant des établissements d'enseignement et de recherche français ou étrangers, des laboratoires publics ou privés. 


\section{Fluropyrimidine single agent or doublet chemotherapy as second line treatment in advanced biliary tract cancer}

Cindy Neuzillet ${ }^{1}$, Andrea Casadei-Gardini ${ }^{2}$, Bertrand Brieau ${ }^{3}$, Caterina Vivaldi ${ }^{4}$, Giovanni Brandi $^{5}$, David Tougeron ${ }^{6}$, Roberto Filippi ${ }^{7}$, Angélique Vienot ${ }^{8}$, Nicola Silvestris ${ }^{9-10}$, Anne-Laure Pointet $^{11}$, Sara Lonardi ${ }^{12}$, Benoît Rousseau ${ }^{13}$, Mario Scartozzi ${ }^{14}$, Laetitia Dahan ${ }^{15}$, Giuseppe Aprile $^{16}$, Samuel Le Sourd ${ }^{17}$, Ludovic Evesque ${ }^{18}$, Aurélia Meurisse ${ }^{19,20}$, Astrid Lièvre ${ }^{21,{ }^{*}}$, Dewi Vernerey ${ }^{19,20, *}$ and the AGEO (Association des Gastro-Entérologues Oncologues) and GICO (Italian Group of Cholangiocarcinoma) investigators

Type: Original Article

Running Title: Overall survival according to second-line regimen in advanced biliary tract cancer

\section{Affiliations:}

1. Medical Oncology Department, Curie Institute, and Versailles Saint-Quentin University, Saint-Cloud, France

2. Department of Oncology and Hematology, Division of Oncology, University of Modena and Reggio Emilia, Modena, Italy

3. Gastroenterology, Cochin University Hospital, Paris, and Gastroenterology Unit, Clinique Jules Verne, Nantes, France

4. University of Pisa, Department of translational research and new technologies in medicine and surgery, Pisa, Italy

5. Oncology, Policlinico S. Orsola-Malpighi, Bologna, Italy

6. Hepato-Gastroenterology, Poitiers University Hospital, Jean Bernard Hôpital, Poitiers, France

7. Department of Oncology, University of Turin, Italy; Centro Oncologico Ematologico Subalpino, Azienda Ospedaliera Universitaria Città della Salute e della Scienza di Torino, Italy

8. Oncology, Besançon University Hospital, Besançon, France

9. Department of Biomedical Sciences and Human Oncology, University of Bari Aldo Moro, Bari, Italy

10. Medical Oncology Unit - IRCCS Istituto Tumori "Giovanni Paolo II" - Bari, Italy

11. Gastroenterology and GI Oncology, George Pompidou European University Hospital, AP-HP, Paris, France

12. Medical Oncology 1 Unit, Istituto Oncologico Veneto, Istituto di Ricovero e Cura a Carattere Scientifico (IRCCS), Padua, Italy 
13. Medical Oncology, Henri Mondor University Hospital, Créteil, France

14. Medical Oncology Unit, University of Cagliari, Cagliari, Italy

15. Pôle "DACCORD" (Digestif, Anatomie pathologique, Chirurgie, CISIH, Oncologie, Radiothérapie, Dermatologie), Service d'Oncologie Digestive, CHU Timone, Marseille, France

16. Department of Oncology, Ospedale San Bortolo, Azienda ULSS8 Berica - Distretto Est, Vicenza, Italy, and Department of Oncology, University Hospital of Udine, Udine, Italy

17. Gastroenterology and Hepatology, Centre Eugène Marquis, Rennes, France

18. Medical Oncology, Centre Antoine Lacassagne, Nice, France

19. Methodology and Quality of Life in Oncology Unit, Besançon University Hospital, Besançon, France

20. Univ. Bourgogne Franche-Comté, INSERM, EFS BFC, UMR1098, Interactions HôteGreffon-Tumeur/Ingénierie Cellulaire et Génique, F-25000 Besançon, France

21. Gastroenterology, Pontchaillou University Hospital, Rennes University, Inserm U1242, Rennes, France

* Co-last authors

\section{Investigators}

AGEO investigators:

- Tarek Boussaha, Oncology, Centre Multidisciplinaire d'Oncologie-CePo, Lausanne, Switzerland

- Alexandra Heurgué, Hepatology and Digestive Oncology, Reims University Hospital, Reims, France

- Jérôme Desramé, Gastroenterology and Hepatology, Jean Mermoz Private Hospital, Lyon, France

- Thierry Lecomte, Hepato-Gastroenterology and GI Oncology, Tours University Hospital, Tours, France

- Wulfran Cacheux, Medical Oncology, Curie Institute, Saint-Cloud, France

- Jean-Baptiste Bachet, Hepato-Gastroenterology and GI Oncology, AP-HP, Pitié-Salpétrière University Hospital, Paris, France

- Jean-Marc Phelip, Hepato-Gastroenterology and GI Oncology, Saint Etienne University Hospital, Saint Etienne, France

- Vincent Hautefeuille, Hepato-Gastroenterology and GI Oncology, Amiens Picardie University Hospital, Amiens, France

- Nassim Hammoudi, Saint Louis University Hospital, AP-HP, Paris, France

- Florence Mary, Gastroenterology, Avicenne University Hospital, AP-HP, Bobigny, France

- Christophe Locher, Hepato-Gastroenterology, Meaux Hospital, Meaux, France

- Anne Bidault-Thirot, Anthony Private Hospital, Anthony, France

- Lysiane Marthey, Béclère University Hospital, AP-HP, Clamart, France 
- Yann Touchefeu, Hepato-Gastroenterology and GI Oncology, Nantes University Hospital, Nantes, France

- Valérie Moulin, Hepato-Gastroenterology, La Rochelle Hospital, La Rochelle, France

- Aziz Zaanan, Gastroenterology and GI Oncology, George Pompidou European University Hospital, AP-HP, Paris, France

- Julien Taïeb, Gastroenterology and GI Oncology, George Pompidou European University Hospital, AP-HP, Paris, France.

GICO investigators:

- Mariaelena Casagrande, Department of Oncology, Azienda Sanitaria Universitaria Friuli Centrale, Udine, Italy.

- Sabina Murgioni, Medical Oncology 1 Unit, Istituto Oncologico Veneto, Istituto di Ricovero e Cura a Carattere Scientifico (IRCCS), Padua, Italy

- Daniele Santini, Department of Medical Oncology, Università 'Campus Bio-Medico di Roma', Rome, Italy

- Lorenzo Fornaro, Unit of Oncology 2, Azienda Ospedaliero-Universitaria Pisana, Pisa, Italy

- Francesco Montagnani, Department of Oncology, Azienda Sanitaria locale di Biella, Ponderano, Italy

- Francesco Leone: Department of Oncology, Azienda Sanitaria Locale di Biella, Ponderano, Italy

- Luca Faloppi, Oncology, University Hospital and University of Cagliari, Cagliari, Italy

- Elisa Giommoni, Azienda ospedaliero-Universitaria Careggi, Florence, Italy

- Stefania Eufemia Lutrino, Department of Medical Oncology, Antonio Perrino Hospital, Brindisi, Italy

- Andrea Palloni, Oncology, Policlinico S. Orsola-Malpighi, Bologna, Italy

- Oronzo Brunetti, Medical Oncology Unit - IRCCS Istituto Tumori "Giovanni Paolo II" - Bari

- Antonella Argentiero, Medical Oncology Unit - IRCCS Istituto Tumori "Giovanni Paolo II" Bari

- Francesca Bergamo, Unit of Oncology 2, Azienda Ospedaliero-Universitaria Pisana, Pisa, Italy

- Enrico Vasile, Unit of Oncology 2, Azienda Ospedaliero-Universitaria Pisana, Pisa, Italy

- Eleonora Lai, Medical Oncology Unit, University of Cagliari, Cagliari, Italy

- Marco Puzzoni, Medical Oncology Unit, University of Cagliari, Cagliari, Italy

- Pina Ziranu, Medical Oncology Unit, University of Cagliari, Cagliari, Italy

- Vincenzo Dadduzio, Medical Oncology 1 Unit, Istituto Oncologico Veneto, Istituto di Ricovero e Cura a Carattere Scientifico (IRCCS), Padua, Italy

- Mario Rizzato, Medical Oncology 1 Unit, Istituto Oncologico Veneto, Istituto di Ricovero e Cura a Carattere Scientifico (IRCCS), Padua, Italy

- Antonio Pellino, Medical Oncology 1 Unit, Istituto Oncologico Veneto, Istituto di Ricovero e Cura a Carattere Scientifico (IRCCS), Padua, Italy

- Massimo Aglietta, Division of Medical Oncology, Candiolo Cancer Institute, FPO-IRCCS, Candiolo (TO), Italy 
- Alessandro Cappetta, Department of Oncology, Ospedale San Bortolo, Azienda ULSS8 Berica

- Distretto Est, Vicenza, Italy

- Silvio Ken Garattini, Department of Medicine (DAME), University of Udine, 33100 Udine (UD), Italy

-Debora Basile, Department of Medicine (DAME), University of Udine, 33100 Udine (UD), Italy.

\section{Corresponding authors:}

Dr. Cindy Neuzillet, M.D., Ph.Doc., Department of Medical Oncology, Curie Institute, Versailles Saint-Quentin University (UVSQ), 35 rue Dailly, 92210 Saint-Cloud, France. E-mail: cindy.neuzillet@gmail.com; Tel: +33 (0)682550492.

Dr. Dewi Vernerey, Ph.D., Methodology and Quality of Life in Oncology Unit (INSERM UMR1098), Besançon University Hospital, 3 boulevard Fleming, 25000 Besançon, France. Email: dvernerey@chu-besancon.fr; Tel: +33 (0)3 70632175.

Key Words: cholangiocarcinoma; palliative chemotherapy; combination chemotherapy; monotherapy; overall survival

Electronic word count: 3339.

Number of figures/tables: $2 / 3$.

\section{Novelty and Impact}

- In two large independent cohorts ( $n=525)$, we showed no overall survival (OS) difference between fluoropyrimidine (FP) monotherapy and doublets as second-line treatment (L2) in advanced biliary tract cancer (aBTC), even after stratification on patient Eastern Cooperative Oncology Group (ECOG) performance status (PS), which is a major prognostic indicator.

- Our results suggest that FP monotherapy is as active as doublets in aBTC in $L 2$, regardless of patient PS, and could be a therapeutic option in this setting. Prospective evaluation in randomized controlled trials is warranted. 


\section{Abbreviations}

5FU: 5-fluorouracil

95\% $\mathrm{Cl}: 95 \%$ confidence interval

aBTC: advanced biliary tract cancer

BSC: best supportive care

BTC: biliary tract cancer

CA19-9: carbohydrate antigen 19-9

CR: complete response

ECOG: Eastern Cooperative Oncology Group

FOLFOX: 5FU, folinic acid, and oxaliplatin

GEMCIS: gemcitabine plus cisplatin

GEMOX: gemcitabine plus oxaliplatin

HR: hazard ratio

IQR: interquartile range

L1: first-line (treatment)

L2: second-line (treatment)

OS: overall survival

PFS: progression-free survival

PS: performance status

XELIRI: capecitabine plus irinotecan 


\section{ABSTRACT}

Fluoropyrimidine (FP) plus platinum chemotherapy has been recently established as a secondline (L2) preferred option in advanced biliary tract cancer (aBTC) (ABC-06 phase III trial). However, the overall survival (OS) benefit was limited and comparison with FP monotherapy was not available. Our aim was to assess the OS of patients treated with a FP monotherapy compared to a doublet with irinotecan or platinum in L2.

We performed a retrospective analysis of two large multicenter prospective cohorts: a French cohort ( 28 centers) and an Italian cohort ( 9 centers). All consecutive patients with aBTC receiving FP-based L2 after GEMCIS/GEMOX L1 between 2003 and 2016 were included. A subgroup analysis according to performance status (PS) and an exploratory analysis according to platinum sensitivity in L1 were planned.

In the French cohort $(n=351)$, no significant OS difference was observed between the FP monotherapy and doublet groups (median OS: 5.6 vs. 6.8 months, $p=0.65$ ). Stratification on ECOG PS showed similar results in PS 0-1 and 2. Median OS was not different between FP monotherapy, platinum- and irinotecan-based doublets (5.6 vs. 7.1 vs. 6.7 months, $p=0.68$ ). Similar findings were observed in the Italian cohort $(n=174)$ and in the sensitivity analysis in pooled cohorts $(n=525)$. No L2 regimen seemed superior over others in the platinum resistant/refractory or sensitive subgroups.

Our results suggest that FP monotherapy is as active as FP doublets in aBTC in L2, regardless of the patient PS and country, and could be a therapeutic option in this setting. 


\section{INTRODUCTION}

Biliary tract carcinoma (BTC) is a rare disease $(<6 / 100,000$ cases per year) yet the second leading cause of primary liver cancer after hepatocellular carcinoma [1]. Most patients are diagnosed at an advanced stage (70\%), not amenable to curative surgery [1]. Chemotherapy with gemcitabine plus cisplatin (GEMCIS) is the reference first-line therapy (L1) in advanced BTC (aBTC), based on the results of the ABC-02 phase III trial [2].

After failure (progression or toxicity) of L1, about one third of patients are eligible for a second line (L2) chemotherapy [3]. Patients with aBTC in the L2 setting display prognostic heterogeneity [3-6]. In a previous work including nearly 800 patients from four independent cohorts, we showed that not all patients seemed to benefit from L2 chemotherapy, and that altered Eastern Cooperative Oncology Group (ECOG) performance status (PS) is the strongest risk factor associated with shorter overall survival (OS) in L2 [7]. We also identified absence of primary tumor resection, L1 discontinuation for progression, presence of peritoneal carcinomatosis, and high carbohydrate antigen $19-9$ (CA19-9) serum level as other independent prognostic biomarkers for OS in this setting [7].

Second-line therapies for aBTC are as well heterogeneous, with no high-level prospective evidence available until recently $[8,9]$. In routine clinical practice, most patients receive fluoropyrimidine (FP, i.e. intravenous 5 fluorouracil [5FU] or oral capecitabine) in monotherapy or combined with platinum or irinotecan, based on retrospective cohorts or small single-arm phase II studies [3, 5-9]. Recently, a randomized phase II study reported 
improved progression-free survival (PFS) using capecitabine plus irinotecan (XELIRI regimen) L2 over single agent irinotecan (median PFS: 3.7 vs. 2.4 months, $p=0.036$ ), with an acceptable safety profile [10]. Moreover, the ABC-06 phase III study, presented at ASCO 2019, showed the superiority of 5FU, folinic acid, and oxaliplatin (FOLFOX regimen) over best supportive care (BSC) in patients with aBTC previously treated with GEMCIS and ECOG PS 0-1 (median OS: 6.2 vs. 5.3 months, hazard ratio $[\mathrm{HR}]: 0.69, p=0.031$ ), with preliminary results suggesting a more pronounced benefit in platinum-resistant (defined by progression within the first three months after the last cycle of GEMCIS L1) or refractory (progression during GEMCIS L1) patients [11]. Based on these results, the National Comprehensive Cancer Network (NCCN) selected FOLFOX as preferred regimen in L2 in advanced BTC. However, the survival benefit was limited (< one month) and no prospective data with FP single-agent are available for comparison. Monotherapy may be non-inferior to combination chemotherapy in this setting [12].

In this study, we aimed to assess the OS according to chemotherapy regimen and ECOG PS (strongest prognostic factor in L2) in patients treated with (i) FP monotherapy vs. combination, and (ii) irinotecan-based vs. platinum-based doublets, in two large independent cohorts.

\section{MATERIAL AND METHODS}

\section{Patients}


All consecutive patients with histologically proven aBTC who were treated between January 2003 and January 2016 in 28 centers were included in the French (AGEO CT2BIL) cohort and their data were retrospectively collected. Patients were considered eligible if they (i) were $\geq$ 18 years old, (ii) had aBTC (metastatic, locally advanced, or recurrent after surgery) not amenable to curative treatment, (iii) had progressed or were intolerant to L1 with gemcitabine plus platinum (GEMCIS or gemcitabine plus oxaliplatin, GEMOX) and (iv) received a FP-based L2 (single agent or combination with irinotecan or platinum). Patients were excluded if they (i) had been treated with gemcitabine plus platinum doublet in the adjuvant setting, (ii) received L1 gemcitabine single-agent, or (iii) had an ampullary carcinoma.

The Italian (GICO) cohort included consecutive patients with aBTC who received L2 between January 2003 and January 2016 with the same inclusion criteria in nine centers.

The database was registered and declared to the National French Commission for bioinformatics data and patient liberty (CNIL) and approved by the Advisory Committee on Information Processing in the field of health research (CCTIRS) (Declaration number: 14-115). An institutional informed non opposition form was signed by all patients with cancer at the time of the first visit in the Departments of Medical Oncology. This form allows use their clinical and biological data for the study. No additional specific consent was necessary for this study according to French regulatory procedures.

For the Italian cohort, the study was reviewed and approved by the Area Vasta Emilia Nord Ethics committee for all participating Italian centers (Protocol number 183/2019). 
Demographics, cancer history and treatment, pathological, clinical, biological, and radiological (tumor response according to Response Evaluation Criteria in Solid Tumors [RECIST] v1.1 criteria) data were retrospectively collected from medical records. Description of the L2 chemotherapy regimens is provided in Supplementary Methods. Dose adjustments due to toxicities and patient PS were carried out according to the investigator's choice.

\section{Statistical Analysis}

Median value (interquartile range) and frequency (percentage) were provided for the description of continuous and categorical variables, respectively. Medians and proportions were compared using Student's $t$ test and chi-square test (or Fisher's exact test, if appropriate), respectively.

The main aim was to assess the OS according to chemotherapy regimen in patients treated with (i) FP monotherapy vs. combination, and (ii) irinotecan-based vs. platinum-based doublets, in two large independent cohorts, with a French (AGEO CT2BIL) and an Italian (GICO) cohorts from two different countries, with different patient populations and clinical practices, to validate the external reproducibility of the results. A sensitivity analysis on the overall population combining the two cohorts was also performed to increase the sample size and assess the robustness of the results obtained from each cohort.

OS with L2 was calculated from the date of first administration of L2 to the date of death from any cause. Survival data were censored at the last follow-up. OS with L2 was estimated using the Kaplan-Meier method and described using median or rate at specific time points with $95 \%$ 
confidence intervals $(95 \% \mathrm{Cl})$. Follow-up duration was calculated using a reverse Kaplan-Meier estimation [13].

Due to the high prognostic weight of ECOG PS, we pre-planned to perform subgroup analyses according to ECOG PS (0-1 vs. 2) [7].

Following the results of the $\mathrm{ABC}-06$ trial, we also considered an exploratory analysis according to platinum sensitivity [11]. Platinum status was determined from L1 GEMCIS/GEMOX, according to the definition used in the $A B C-06$ trial [11]: sensitive (progression after three months of the last administration of platinum), refractory (progression under platinum chemotherapy), and resistant (progression within the first three months after completion the last administration of platinum).

Finally, post-hoc power calculations to detect a minimal clinically meaningful difference in OS with doublet vs. monotherapy, defined as $H R \leq 0.70$ (grade 2) or $H R \leq 0.65$ (grade 3) based on ESMO magnitude of benefit scale v1.1 [14], were performed in each cohort.

All analyses were performed using SAS version 9.4 and R software version 2.15.2. $P$ values of less than 0.05 were considered statistically significant, and all tests were two-sided.

\section{RESULTS}

\section{Population-based prospective cohorts}

The French (AGEO CT2BIL) cohort included 351 patients treated in L1 with GEMOX (92\%) or GEMCIS (8\%) and in L2 with a FP alone or combined with platinum or irinotecan) in 28 centers 
[Table 1]. With a median follow-up since the beginning of L2 chemotherapy of 34.0 months (95\%Cl=28.9-51.4), 299 (85.2\%) patients had died.

The Italian (GICO) cohort included 174 patients with the same inclusion criteria treated in nine centers. The two cohorts displayed statistically significant differences in terms of (i) biliary drainage, (ii) type of $\mathrm{L} 1$ regimen, (iii) reason for $\mathrm{L} 1$ discontinuation, (iv) ECOG PS at the beginning of $L 2,(v)$ lymph node and (vi) peritoneal metastases, (vii) type of $L 2$ regimen, and (viii) third-line (L3) administration [Table 1].

\section{Fluoropyrimidine monotherapy vs. doublet in the French (AGEO CT2BIL) cohort}

In the French cohort, patients receiving L2 with FP monotherapy had more often ECOG PS 2 compared with patients receiving a doublet chemotherapy $(47.5 \%$ vs. $28.0 \%, p=0.010)$ and displayed higher bilirubin and CA19-9 levels (albeit with a high rate of missing data for these two biological variables) ( $p=0.028$ and $p=0.035$, respectively) [Table 2]. Patient characteristics in the two groups were otherwise similar [Table 2].

No significant OS difference was observed between the two groups (doublet vs. monotherapy) in the overall cohort (median OS: 6.8 vs. 5.6 months, $\mathrm{HR}: 0.936,95 \% \mathrm{Cl}: 0.701$ to $1.250, p=0.65$ )

[Figure 1A]. Subgroup analyses according to ECOG PS showed similar results in patients with ECOG PS 0-1 (median OS: 7.8 vs. 8.4 months, HR: $1.127,95 \% \mathrm{Cl}: 0.750$ to $1.694, p=0.57$ ) [Figure 1B] and ECOG PS 2 (median OS: 4.0 vs. 3.2 months, HR: $1.005,95 \% \mathrm{Cl}: 0.637$ to $1.586, p=0.98$ ) [Figure 1C]. There was no difference according to the localization of the primary tumor 
between FP monotherapy or doublet, in intrahepatic cholangiocarcinoma $(p=0.49)$, in extrahepatic cholangiocarcinoma $(p=0.94)$ and in gallbladder cancer $(p=0.82)$.

\section{Fluoropyrimidine monotherapy vs. doublet in the Italian (GICO) cohort}

Similar results were obtained in the Italian cohort: no significant OS difference between FP doublet vs. monotherapy (HR: $0.782,95 \% \mathrm{Cl}: 0.556$ to $1.10, p=0.16$ ) [Table 3 and Figure $1 \mathrm{D}$ ]. No benefit of doublet chemotherapy vs. monotherapy was observed across the ECOG PS subgroups [Figure $1 \mathrm{E}-\mathrm{F}]$.

\section{Monotherapy vs. platinum-based vs. irinotecan-based doublet in the French (AGEO CT2BIL)}

\section{cohort}

Patients receiving platinum-based chemotherapy $(n=94,26.8 \%$; which consisted in a platinum switch in most patients: oxaliplatin to cisplatin/carboplatin or cisplatin to oxaliplatin) were less likely to have stopped L1 for disease progression than those receiving irinotecan-based chemotherapy (68.1\% vs. $86.6 \%, p=0.0009)$ [Table 2]. In addition, patients in the FP plus platinum doublet group had more often locally advanced tumors (9.6\% vs. 3.1\%, $p=0.043$ ), and less frequent lymph node and bone metastases $(p=0.010$ and $p=0.016$, respectively) [Table 2]. ECOG PS distribution was not different between these two groups ( $p=0.077)$. No significant OS difference was observed between the three groups (median OS: 5.6 vs. 7.1 vs. 6.7 months in FP monotherapy, vs. FP plus platinum vs. FP plus irinotecan doublet, respectively, HR: $0.879,95 \% \mathrm{Cl}: 0.629$ to 1.227 for platinum doublet vs. monotherapy and HR: 
0.972, $95 \% \mathrm{Cl}$ : 0.717 to 1.319 for irinotecan doublet vs. monotherapy, $p=0.68$ ) [Figure $2 \mathrm{~A}$ ]. Stratification on ECOG PS showed similar results in PS 0-1 (median OS: 8.4 vs. 11.1 vs. 7.5 months, HR: $1.007,95 \% \mathrm{Cl}: 0.636$ to 1.595 for platinum doublet vs. monotherapy vs. and HR: $1.202,95 \% \mathrm{Cl}: 0.788$ to 1.835 for irinotecan doublet vs. monotherapy, $p=0.47$ ) [Figure $2 \mathrm{~B}$ ] and 2 (median OS: 3.2 vs. 4.1 vs. 4.0 months, HR: $1.089,95 \% \mathrm{Cl}: 0.615$ to 1.928 for platinum doublet vs. monotherapy and HR: $0.969,95 \% \mathrm{Cl}$ : 0.596 to 1.576 for irinotecan doublet vs. monotherapy, $p=0.90$ ) subgroups [Figure $2 \mathrm{C}$ ].

\section{Platinum-based and irinotecan-based doublet in the Italian (GICO) cohort}

Similar results were obtained in the Italian cohort: no significant OS difference between FP monotherapy vs. FP plus platinum vs. FP plus irinotecan doublets (median OS: 5.2 vs. 6.0 vs. 7.5 months in FP monotherapy, vs. FP plus platinum vs. FP plus irinotecan doublet, HR: 1.140 95\% Cl: 0.634 to 2.053 for platinum doublet vs. monotherapy and $\mathrm{HR}: 0.709,95 \% \mathrm{Cl}: 0.487$ to 1.031 for irinotecan doublet vs. monotherapy, $p=0.14$ ) [Table 3 and Figure 2D]. As reported in the French cohort, patients receiving platinum-based doublet $(n=16,9.2 \%)$ were more likely to have stopped L1 owing to toxicity or other reason rather than disease progression $(p=0.019)$. In contrast, there was no significant imbalance in ECOG PS distribution between monotherapy and doublet regimens in the Italian cohort $(p=0.23)$. No OS difference was observed across the ECOG PS subgroups [Figure 2E-F].

\section{Sensitivity analysis in the pooled cohorts}


In order to increase the sample size and study power, we performed a sensitivity analysis on the overall population combining the two cohorts ( $n=524$ patients evaluable for OS). Our results were validated in this pooled cohort, with no significant OS difference between FP doublet chemotherapy vs. monotherapy (median OS: 6.8 vs. 5.6 months, $\mathrm{HR}: 0.879,95 \% \mathrm{Cl}$ : 0.721 to $1.072, p=0.20$ in the overall population and median OS: 7.5 vs. 7.8 months, HR: 0.950 , 95\% $\mathrm{Cl}$ : 0.742 to $1.215, p=0.68$ in the ECOG PS $0-1$ subgroup, respectively), and between monotherapy vs. FP plus platinum vs. FP plus irinotecan doublets (median OS: 5.6 vs. 6.8 vs. 6.7 months, HR: $0.87595 \% \mathrm{Cl}: 0.679$ to 1.128 for platinum doublet vs. monotherapy vs. and HR: $0.881,95 \% \mathrm{Cl}: 0.710$ to 1.092 for irinotecan doublet $v s$. monotherapy, $p=0.44$ in the overall population and median OS: 7.8 vs. 8.4 vs. 7.5 months, HR: $0.909,95 \% \mathrm{Cl}: 0.664$ to 1.245 for platinum doublet vs. monotherapy vs. and HR: $0.971,95 \% \mathrm{Cl}: 0.746$ to 1.264 for monotherapy vs. irinotecan doublet, $p=0.83$ in the ECOG PS 0-1 subgroup) [Supplementary Table 1 and Supplementary Figure 1].

\section{Exploratory analysis according to platinum sensitivity}

We further analyzed patient OS with FP monotherapy, platinum or irinotecan doublet L2 based on their platinum sensitivity (sensitive vs. resistant/refractory) in L1 [Supplementary Table 2A and 2B] [11]. In the French cohort, no significant OS difference was found between the different L2 regimens in the platinum resistant/refractory subgroup (median OS: 5.3, 6.5, and 6.1 months, with FP monotherapy, FP plus platinum, and FP plus irinotecan, respectively, $p=0.63$ ) [Supplementary Figure $2 \mathrm{~A}$ ] and a non-significant OS trend in favor of FP plus irinotecan 
was observed in the platinum sensitive subgroup (median OS: 5.6, 5.4, and 9.9 months, $p=0.16$; FP plus irinotecan vs. FP plus platinum: $\mathrm{HR}: 0.602,95 \% \mathrm{Cl}: 0.356-1.017, p=0.058$ ) [Supplementary Figure 2B]. Of note, patients who received FP plus irinotecan doublet in this subgroup had more often ECOG PS 0-1 (82.9\% vs. 53.9\% in the FP plus platinum doublet, $p=0.031)$, and the OS trend in favor of FP plus irinotecan disappeared when we considered only patients with PS $0-1$ (HR: $0.924,95 \% \mathrm{Cl}: 0.465$ to $1.834, p=0.82$ ), showing that it was driven by the imbalance in ECOG PS distribution. This favorable survival trend with irinotecan-based doublet was not observed in the Italian cohort, where there was no OS difference between the regimens according to platinum sensitivity [Supplementary Table 3A-B and Supplementary Figure 2C-D]. Similar results were obtained in the sensitivity analysis on pooled cohorts (FP plus irinotecan vs. FP plus platinum: in platinum sensitive patients, HR: $0.589,95 \% \mathrm{Cl}: 0.365$ 0.951, $p=0.031$ and HR: $0.866,95 \% \mathrm{Cl}: 0.475$ to $1.579, p=0.64$ in overall population and ECOG PS 0-1, respectively; in platinum resistant patients, $\mathrm{HR}$ : $0.993,95 \% \mathrm{Cl}: 0.721$ to $1.367, p=0.96$ and HR: $0.839,95 \% \mathrm{Cl}: 0.574$ to $1.227, p=0.37$ in overall population and ECOG PS $0-1$, respectively).

\section{Post-hoc power calculations}

Post-hoc power calculations to detect a significant association between treatment (doublet vs. monotherapy) and OS based on ESMO magnitude of benefit scale v1.1 [14] were provided in Supplementary Table 4. 


\section{DISCUSSION}

Beyond failure of $\mathrm{L} 1$, up to $30 \%-40 \%$ of aBTC patients remain in a good clinical condition and are able to receive subsequent line(s) of therapy [10]. Until 2019, there was no recommended regimen in this setting and the type of chemotherapy regimen varied according to the center/national clinical practices [2, 3]. Following the presentation of the results of the ABC06 phase III trial, FOLFOX chemotherapy has become the preferred option in patients previously treated with GEMCIS, albeit with a modest OS benefit [11]. These results are not applicable to patients treated with GEMOX in L1 and FOLFOX has not been compared to any other chemotherapy regimen in L2. Overall, there is insufficient evidence to recommend specific regimens for $\mathrm{L} 2$ in aBTC patients, and prospective randomized trials are needed.

In this study, we demonstrated, using two large independent cohorts gathering a total of 525 patients, that there was no OS difference between FP monotherapy and doublets, even after stratification on patient ECOG PS, which is a major prognostic indicator [7]. We analysed first each cohort (France and Italy) separately to validate the external reproducibility of our results. Even though the data were retrospectively collected, our study population is well-annotated, with a low rate of missing data, and the results were reproduced in both cohorts despite differences in several factors including type of L1 regimen, reason for L1 discontinuation, ECOG PS at the beginning of L2, type of L2 regimen, and L3 administration, thereby highlighting their robustness. Moreover, the overall population (pooled cohorts) is the largest cohort available in $\mathrm{ABTC}$ in the $\mathrm{L} 2$ setting. The power to detect a HR $\leq 0.70$ in each cohort separately was limited but the complementary analysis on the overall population $(n=524$ 
patients evaluable for OS) allowed us to rule out a clinically meaningful difference in OS between FP monotherapy or doublets with a high statistical power of $93 \%$, and had a sufficient power $(\geq 80 \%)$ to detect a difference of 1.9 months in median OS.

Although evidence of activity of capecitabine is available in BTC in the adjuvant setting (BILCAP phase III study [15]), data regarding FP monotherapy in aBTC, and particularly in L2, are limited. Only one small randomized phase II trial evaluated capecitabine alone or combined with mitomycine $\mathrm{C}$ in 57 patients with aBTC: the results were disappointing with a 6-month PFS rate of $8 \%$ with capecitabine and $10 \%$ with capecitabine plus mitomycine $C$ [16]. In Asian countries, three single-arm phase II trials with S-1 monotherapy after progression on L1 chemotherapy suggested that this compound was safe and moderately efficacious in L2 [1719]. Retrospective cohorts and meta-analyses reported conflicting results about the efficacy of FP doublets vs. monotherapy [3, 5-9, 12]. Single-agent FP are expected to be less toxic and our results suggest that they may be as effective as doublets in $L 2$, thereby representing a potentially interesting option in this setting where health related quality of life is a central issue. In particular, in the subset of patients with ECOG PS 0-1, median OS with FP monotherapy reached 8.4 and 7.3 months in the French and Italian cohorts, respectively, which compared favorably with the OS of patients treated with FOLFOX in the ABC-06 study. This trial lacked a FP monotherapy arm for proper comparison. The ongoing NALIRICC randomized Phase II trial (NCT03043547) is evaluating 5FU plus Nal-IRI combination vs. 5FU in patients with advanced BTC in $L 2$, and will provide prospective data to answer to this question. 
In addition, the question of the best chemotherapy regimen in $L 2$ according to response to $L 1$ is still unanswered and has been recently put under the spotlight following preliminary subgroup analyses from the $A B C-06$ trial, which showed that patients with platinum resistant/refractory disease (62.3\%) seemed to benefit the most from FOLFOX L2 (HR [95\%Cl]: $0.63[0.41-0.96]$ vs. $0.81[0.47-1.4]$ in the platinum sensitive group) [11]. In our study, no association was observed between platinum sensitivity and OS with the different regimens (FP monotherapy, FP plus platinum doublet, or FP plus irinotecan doublet), and the nonsignificant trend in favor of irinotecan in platinum sensitive patients was explained by an imbalance in patient ECOG PS. However, patients receiving platinum-based chemotherapy represented a small subgroup of patients $(26.8 \%$ in the French cohort and $9.2 \%$ in the Italian cohort), were more likely to have stopped L1 for reasons other than disease progression, and had more often altered ECOG PS in the French cohort. Therefore, our results are limited by small sample size and potential confounding bias, and additional prospective studies are warranted to draw definitive conclusions.

In summary, we previously showed that all patients with aBTC do not benefit from L2 administration and that the CT2BIL score (mainly driven by ECOG PS) may be useful in this setting [7]. In the present article, our results suggest that FP monotherapy is as active as FP doublets in aBTC in L2, regardless of the patient PS and platinum sensitivity status, and could be a therapeutic option in this setting. This would warrant further prospective evaluation in randomized controlled trials. 
In the next future, the management of patients with aBTC may change with the advent of active targeted therapies in specific molecular subsets (fibroblast growth factor receptor 2 [FGFR2], isocitrate dehydrogenase 1 [IDH1], and neurotrophic tyrosine receptor kinase [NTRK] gene alterations, and microsatellite instability [MSI]); positive results from Phase II and III trials have been recently presented, which were not available at the time our study was performed [20-24]. Therefore, in patients with aBTC who are fit for L2 (CT2BIL score/ECOG PS) after progression under gemcitabine/platinum L1, performing a molecular profiling of the tumor may allow patient access to personalized targeted therapy beside classical chemotherapy, opening new therapeutic opportunities to improve patient's survival and quality of life. 
Conflict of Interest: There are no competing financial interests in relation to the work described.

Financial support: No specific funding.

\section{Authors' contribution:}

Design of the work: Cindy Neuzillet, Astrid Lièvre, Dewi Vernerey

Acquisition of data: Cindy Neuzillet, Andrea Casadei Gardini, Bertrand Brieau, Caterina Vivaldi, Giovanni Brandi, David Tougeron, Roberto Filippi, Angélique Vienot, Nicola Silvestris, AnneLaure Pointet, Sara Lonardi, Benoît Rousseau, Mario Scartozzi, Laetitia Dahan, Giuseppe Aprile, Samuel Le Sourd, Ludovic Evesque, Astrid Lièvre

Data management: Cindy Neuzillet, Aurélia Meurisse

Analysis/interpretation of data: Cindy Neuzillet, Astrid Lièvre, Dewi Vernerey

Manuscript writing: Cindy Neuzillet, Astrid Lièvre, Dewi Vernerey

Manuscript revision and approval: all authors

\section{Data accessibility:}

The data that support the findings of this study are available on request from the corresponding author. The data are not publicly available due to privacy or ethical restrictions.

\section{Ethical approval:}

The database was registered and declared to the National French Commission for bioinformatics data and patient liberty (CNIL) and approved by the Advisory Committee on Information Processing in the field of health research (CCTIRS) (Declaration number: 14-115). An institutional informed non opposition form was signed by all patients with cancer at the time of the first visit in the Departments of Medical Oncology. This form allows use their 
clinical and biological data for the study. No additional specific consent was necessary for this study according to French regulatory procedures.

For the Italian cohort, the study was reviewed and approved by the Area Vasta Emilia Nord Ethics committee for all participating Italian centers (Protocol number 183/2019). 


\section{REFERENCES}

1. Valle JW, Borbath I, Khan SA et al. Biliary cancer: ESMO Clinical Practice Guidelines for diagnosis, treatment and follow-up. Ann Oncol 2016; 27: v28-v37.

2. Valle J, Wasan $\mathrm{H}$, Palmer DH et al. Cisplatin plus gemcitabine versus gemcitabine for biliary tract cancer. N Engl J Med 2010; 362: 1273-1281.

3. Brieau B, Dahan L, De Rycke Y et al. Second-line chemotherapy for advanced biliary tract cancer after failure of the gemcitabine-platinum combination: A large multicenter study by the Association des Gastro-Enterologues Oncologues. Cancer 2015; 121: 32903297.

4. Fornaro L, Cereda S, Aprile G et al. Multivariate prognostic factors analysis for second-line chemotherapy in advanced biliary tract cancer. Br J Cancer 2014; 110: 21652169.

5. Fornaro L, Vivaldi C, Cereda S et al. Second-line chemotherapy in advanced biliary cancer progressed to first-line platinum-gemcitabine combination: a multicenter survey and pooled analysis with published data. J Exp Clin Cancer Res 2015; 34: 156.

6. Kim BJ, Yoo C, Kim KP et al. Efficacy of fluoropyrimidine-based chemotherapy in patients with advanced biliary tract cancer after failure of gemcitabine plus cisplatin: retrospective analysis of 321 patients. Br J Cancer 2017; 116: 561-567.

7. Neuzillet C, Casadei Gardini A, Brieau B et al. Prediction of survival with secondline therapy in biliary tract cancer: Actualisation of the AGEO CT2BIL cohort and European multicentre validations. Eur J Cancer 2019; 111: 94-106.

8. Lamarca A, Hubner RA, David Ryder W, Valle JW. Second-line chemotherapy in advanced biliary cancer: a systematic review. Ann Oncol 2014; 25: 2328-2338.

9. Adeva J, Sangro B, Salati M et al. Medical treatment for cholangiocarcinoma. Liver Int 2019; 39 Suppl 1: 123-142.

10. Zheng $\mathrm{Y}, \mathrm{Tu} \mathrm{X}$, Zhao $\mathrm{P}$ et al. A randomised phase II study of second-line XELIRI regimen versus irinotecan monotherapy in advanced biliary tract cancer patients progressed on gemcitabine and cisplatin. Br J Cancer 2018; 119: 291-295.

11. Lamarca A, Palmer DH, Wasan HS et al. ABC-06 | A randomised phase III, multicentre, open-label study of Active Symptom Control (ASC) alone or ASC with oxaliplatin / 5-FU chemotherapy (ASC + mFOLFOX) for patients with locally advanced / metastatic biliary tract cancers (ABC) previously-treated with cisplatin/gemcitabine (CisGem) chemotherapy. ASCO meeting 2019 2019; Abstract \#4003.

12. Ying J, Chen J. Combination versus mono-therapy as salvage treatment for advanced biliary tract cancer: A comprehensive meta-analysis of published data. Crit Rev Oncol Hematol 2019; 139: 134-142.

13. Schemper M, Smith TL. A note on quantifying follow-up in studies of failure time. Control Clin Trials 1996; 17: 343-346.

14. Cherny NI, Dafni U, Bogaerts J et al. ESMO-Magnitude of Clinical Benefit Scale version 1.1. Ann Oncol 2017; 28: 2340-2366.

15. Primrose JN, Fox RP, Palmer DH et al. Capecitabine compared with observation in resected biliary tract cancer (BILCAP): a randomised, controlled, multicentre, phase 3 study. Lancet Oncol 2019; 20: 663-673. 
16. Cereda S, Milella M, Cordio S et al. Capecitabine with/without mitomycin C: results of a randomized phase II trial of second-line therapy in advanced biliary tract adenocarcinoma. Cancer Chemother Pharmacol 2016; 77: 109-114.

17. Sasaki T, Isayama $\mathrm{H}$, Yashima $\mathrm{Y}$ et al. S-1 monotherapy in patients with advanced biliary tract cancer. Oncology 2009; 77: 71-74.

18. Sasaki T, Isayama H, Nakai Y et al. Multicenter phase II study of S-1 monotherapy as second-line chemotherapy for advanced biliary tract cancer refractory to gemcitabine. Invest New Drugs 2012; 30: 708-713.

19. Suzuki E, Ikeda M, Okusaka $\mathrm{T}$ et al. A multicenter phase II study of S-1 for gemcitabine-refractory biliary tract cancer. Cancer Chemother Pharmacol 2013; 71: 1141-1146.

20. Vogel A, Sahai V, Hollebecque A et al. FIGHT-202: a phase 2 study of pemigatinib in patients (pts) with previously treated locally advanced or metastatic cholangiocarcinoma (CCA). ESMO meeting 2019 Abstract LBA 40.

21. Abou-Alfa GK, Macarulla Mercade T, Javle M et al. ClarIDHy: A global, phase 3, randomized, double-blind study of ivosidenib (IVO) vs placebo in patients with advanced cholangiocarcinoma (CC) with an isocitrate dehydrogenase 1 (IDH1) mutation. ESMO meeting 2019 Abstract LBA 10.

22. Drilon A, Laetsch TW, Kummar S et al. Efficacy of Larotrectinib in TRK FusionPositive Cancers in Adults and Children. N Engl J Med 2018; 378: 731-739.

23. Le DT, Durham JN, Smith KN et al. Mismatch repair deficiency predicts response of solid tumors to PD-1 blockade. Science 2017; 357: 409-413.

24. Verlingue L, Malka D, Allorant A et al. Precision medicine for patients with advanced biliary tract cancers: An effective strategy within the prospective MOSCATO-01 trial. Eur J Cancer 2017; 87: 122-130. 


\section{TABLES}

Table 1. Patient characteristics in the two cohorts.

\begin{tabular}{|c|c|c|c|}
\hline & $\begin{array}{c}\text { France (AGEO CT2BIL) } \\
(n=351)\end{array}$ & $\begin{array}{c}\text { Italy (GICO) } \\
(n=174)\end{array}$ & $p$-value \\
\hline \multicolumn{4}{|l|}{ Sex } \\
\hline Male & $193(55.0 \%)$ & $87(50.0 \%)$ & 0.28 \\
\hline Age - years, median (IQR) & $65.4(58.2-71.5)$ & $65.5(57.3-70.4)$ & 0.34 \\
\hline Missing & 0 & 1 & \\
\hline \multicolumn{4}{|l|}{ Primary tumor site } \\
\hline Intra-hepatic & $180(51.4 \%)$ & $103(59.2 \%)$ & 0.12 \\
\hline Extra-hepatic/hilar & $101(28.9 \%)$ & $36(20.7 \%)$ & \\
\hline Gallbladder & 69 (19.7\%) & $35(20.1 \%)$ & \\
\hline Missing & 1 & 0 & \\
\hline \multicolumn{4}{|l|}{ Prior resection of primary tumor ${ }^{\#, *}$} \\
\hline Yes & $90(25.6 \%)$ & $51(29.3 \%)$ & 0.37 \\
\hline \multicolumn{4}{|l|}{ Radiotherapy } \\
\hline Yes & $24(6.9 \%)$ & $12(6.9 \%)$ & 1.00 \\
\hline Missing & 3 & 0 & \\
\hline \multicolumn{4}{|l|}{ Biliary drainage } \\
\hline Yes & 119 (34.5\%) & $42(24.3 \%)$ & 0.018 \\
\hline Missing & 6 & 1 & \\
\hline \multicolumn{4}{|l|}{ Type of L1 regimen" } \\
\hline Gemcitabine + oxaliplatin & $322(91.7 \%)$ & $93(53.5 \%)$ & $<0.0001$ \\
\hline Gemcitabine + cisplatin & $29(8.3 \%)$ & $81(46.6 \%)$ & \\
\hline \multicolumn{4}{|l|}{ Best response to $\mathrm{L1}$} \\
\hline$C R$ & $14(4.0 \%)$ & $1(0.6 \%)$ & 0.055 \\
\hline$P R / S D$ & $208(59.8 \%)$ & $99(57.5 \%)$ & \\
\hline$P D$ & $126(36.2 \%)$ & $72(41.9 \%)$ & \\
\hline Missing & 3 & 2 & \\
\hline Duration of L1 - months, median (IQR) ${ }^{* *}$ & $5.9(3.2-10.9)$ & $5.9(3.5-8.8)$ & 0.80 \\
\hline Missing & 0 & 2 & \\
\hline \multicolumn{4}{|l|}{ Reason for L1 discontinuation } \\
\hline Toxicity & $32(9.1 \%)$ & $11(6.4 \%)$ & 0.013 \\
\hline Other & $39(11.1 \%)$ & $35(20.5 \%)$ & \\
\hline$P D$ & $280(79.8 \%)$ & $125(73.1 \%)$ & \\
\hline Missing & 0 & 3 & \\
\hline \multicolumn{4}{|l|}{ PS at the beginning of L2 } \\
\hline 0 & $54(16.1 \%)$ & $52(30.2 \%)$ & 0.0003 \\
\hline 1 & $176(52.4 \%)$ & $85(49.4 \%)$ & \\
\hline 2 & $106(31.5 \%)$ & $35(20.4 \%)$ & \\
\hline Missing & 15 & 2 & \\
\hline \multicolumn{4}{|l|}{ Disease stage at the beginning of $\mathrm{L2}$} \\
\hline Metastatic & $333(94.9 \%)$ & $167(96.5 \%)$ & 0.39 \\
\hline Locally advanced & $18(5.1 \%)$ & $6(3.5 \%)$ & \\
\hline Missing & 0 & 1 & \\
\hline \multicolumn{4}{|l|}{ Metastatic sites } \\
\hline Liver $^{\#}-$ yes & $216(61.5 \%)$ & $113(64.9 \%)$ & 0.48 \\
\hline
\end{tabular}




\begin{tabular}{|c|c|c|c|}
\hline Lung - yes & $102(29.1 \%)$ & $52(30.1 \%)$ & 0.81 \\
\hline Missing & 0 & 1 & \\
\hline Bone - yes & $34(9.7 \%)$ & $18(10.5 \%)$ & 0.78 \\
\hline Missing & 0 & 2 & \\
\hline Lymph node - yes & $130(37.0 \%)$ & 95 (54.9\%) & 0.0001 \\
\hline Missing & 0 & 1 & \\
\hline Peritoneum - yes & $133(37.9 \%)$ & $49(28.3 \%)$ & 0.031 \\
\hline Missing & 0 & 1 & \\
\hline Total bilirubin $-\mu \mathrm{mol} / \mathrm{L}$, median (IQR) & $12.0(7.0-17.0)$ & $10.3(7.5-16.6)$ & 0.73 \\
\hline Missing & 91 & 34 & \\
\hline Albumin - g/L, median (IQR) & $34.1(30.0-38.0)$ & $35.0(29.0-39.0)$ & 0.44 \\
\hline Missing & 208 & 73 & \\
\hline $\begin{array}{l}\text { Serum CA19-9 - UI/mL, median (IQR) } \\
\text { Missing }\end{array}$ & $\begin{array}{c}169.0(44.5-1291.0) \\
135\end{array}$ & $\begin{array}{l}150.0(38.8- \\
973.2) \\
31\end{array}$ & 0.74 \\
\hline \multicolumn{4}{|l|}{ Type of L2 regimen ${ }^{\#}$} \\
\hline Fluoropyrimidine monotherapy & $63(17.9 \%)$ & $98(56.3 \%)$ & $<0.0001$ \\
\hline Fluoropyrimidine + irinotecan & $194(55.3 \%)$ & $60(34.5 \%)$ & \\
\hline Fluoropyrimidine + platinum & $94(26.8 \%)$ & $16(9.2 \%)$ & \\
\hline \multicolumn{4}{|l|}{ L3 chemotherapy } \\
\hline Yes & $150(43.5 \%)$ & $46(26.4 \%)$ & 0.0002 \\
\hline Missing & 6 & 0 & \\
\hline \multicolumn{4}{|c|}{$\begin{array}{l}{ }^{*} \text { Prior resection of the primary tumor was defined as surgery with R0/R1 resection and no evidence of disease } \\
\text { within one month post-surgery }\end{array}$} \\
\hline \multicolumn{4}{|l|}{$\mathrm{L} 2$} \\
\hline \multicolumn{4}{|c|}{$\begin{array}{l}\text { CA19-9: carbohydrate antigen 19-9, CR: complete response, IQR: interquartile range, L1: first-line treatment, } \\
\text { L2: second-line treatment, L3: third-line treatment, PD: progressive disease, PR: partial response, PS: } \\
\text { performance status, SD: stable disease }\end{array}$} \\
\hline
\end{tabular}


Table 2. Patient characteristics in the French (AGEO CT2BIL) cohort according to monotherapy, irinotecan-based or platinum-based combination regimen in second line.

\begin{tabular}{|c|c|c|c|c|c|c|}
\hline & \\
\hline & $\begin{array}{l}\text { Fluoropyrimidine } \\
\text { monotherapy } \\
(n=63)\end{array}$ & $\begin{array}{l}\text { Fluoropyrimidine }+ \\
\text { irinotecan }(n=194) \text { or } \\
\text { Fluoropyrimidine }+ \\
\text { platinum }(n=94) \\
(n=288)\end{array}$ & p-value & $\begin{array}{c}\text { Fluoropyrimidine } \\
+ \text { irinotecan } \\
(n=194)\end{array}$ & $\begin{array}{l}\text { Fluoropyrimidine } \\
+ \text { platinum } \\
(n=94)\end{array}$ & p-value $\#$ \\
\hline \multicolumn{7}{|c|}{ 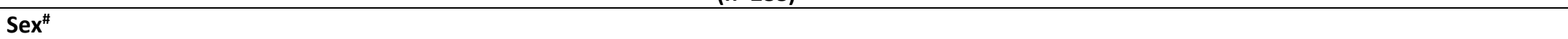 } \\
\hline Male & $36(57.1 \%)$ & $157(54.5 \%)$ & 0.70 & $101(52.1 \%)$ & $56(59.6 \%)$ & 0.23 \\
\hline Age $^{\#}$ - years, median (IQR) & $66.9(60.6-71.7)$ & $65.0(57.9-71.4)$ & 0.24 & 64.7 (58.2- 70.4) & $66.1(56.8-72.7)$ & 0.69 \\
\hline \multicolumn{7}{|l|}{ Primary tumor site } \\
\hline Intrahepatic & $40(63.5 \%)$ & $140(48.8 \%)$ & 0.10 & $95(49.0 \%)$ & 45 (48.4\%) & 0.31 \\
\hline Extrahepatic/hilar & $13(20.6 \%)$ & $88(30.7 \%)$ & & $55(28.4 \%)$ & $33(35.5 \%)$ & \\
\hline Gallbladder & $10(15.9 \%)$ & $59(20.6 \%)$ & & $44(22.7 \%)$ & $15(16.1 \%)$ & \\
\hline Missing & 0 & 1 & & 0 & 1 & \\
\hline \multicolumn{7}{|c|}{ Prior resection of primary tumor ${ }^{\#, *}$} \\
\hline Yes & $12(19.1 \%)$ & $78(27.1 \%)$ & 0.19 & $46(23.7 \%)$ & $32(34.0 \%)$ & 0.064 \\
\hline \multicolumn{7}{|l|}{ Radiotherapy } \\
\hline Yes & $7(11.1 \%)$ & $17(6.0 \%)$ & 0.17 & $8(4.2 \%)$ & $9(9.6 \%)$ & 0.071 \\
\hline Missing & 0 & 3 & & 3 & 0 & \\
\hline \multicolumn{7}{|l|}{ Biliary drainage } \\
\hline Yes & $18(29.0 \%)$ & $101(35.7 \%)$ & 0.32 & $65(34.4 \%)$ & $36(38.3 \%)$ & 0.52 \\
\hline Missing & 1 & 5 & & 5 & 0 & \\
\hline \multicolumn{7}{|l|}{ Type of L1 regimen } \\
\hline Gemcitabine + oxaliplatin & $61(96.8 \%)$ & $261(90.6 \%)$ & 0.11 & $174(89.7 \%)$ & 87 (92.5\%) & 0.43 \\
\hline Gemcitabine + cisplatin & $2(3.2 \%)$ & 27 (9.4\%) & & $20(10.3 \%)$ & $7(7.5 \%)$ & \\
\hline
\end{tabular}




\begin{tabular}{|c|c|c|c|c|c|c|}
\hline \multicolumn{7}{|l|}{ Best response to L1 } \\
\hline$C R$ & $2(3.2 \%)$ & $12(4.2 \%)$ & 0.63 & $8(4.1 \%)$ & $4(4.3 \%)$ & 0.051 \\
\hline$P R / S D$ & $41(65.1 \%)$ & $167(58.6 \%)$ & & $104(53.9 \%)$ & $63(68.5 \%)$ & \\
\hline$P D$ & $20(31.7 \%)$ & $106(37.2 \%)$ & & $81(42.0 \%)$ & $25(27.2 \%)$ & \\
\hline Missing & 0 & 3 & & 1 & 2 & \\
\hline Duration of L1 - months ${ }^{\#, * *}$ & $6.9(3.5-11.5)$ & $5.5(3.2-10.7)$ & 0.34 & $5.3(3.2-10.8)$ & $6.5(3.2-10.0)$ & 0.58 \\
\hline \multicolumn{7}{|l|}{ Reason for L1 discontinuation ${ }^{a}$} \\
\hline Toxicity & $7(11.1 \%)$ & $25(8.7 \%)$ & 0.73 & $11(5.7 \%)$ & $14(14.9 \%)$ & 0.0009 \\
\hline $\begin{array}{l}\text { Other } \\
P D\end{array}$ & $8(12.7 \%)$ & $31(10.8 \%)$ & & $15(7.7 \%)$ & $16(17.0 \%)$ & \\
\hline$P D$ & $48(76.2 \%)$ & $232(80.6 \%)$ & & $168(86.6 \%)$ & $64(68.1 \%)$ & \\
\hline \multicolumn{7}{|l|}{ PS at the beginning of $L 2$} \\
\hline 0 & $9(14.8 \%)$ & 45 (16.4\%) & 0.010 & 25 (13.1\%) & $20(23.8 \%)$ & 0.077 \\
\hline 1 & $23(37.7 \%)$ & $153(55.6 \%)$ & & $112(58.6 \%)$ & $41(48.8 \%)$ & \\
\hline 2 & $29(47.5 \%)$ & 77 (28.0\%) & & $54(28.3 \%)$ & $23(27.4 \%)$ & \\
\hline Missing & 2 & 13 & & 3 & 10 & \\
\hline \multicolumn{7}{|l|}{$\begin{array}{l}\text { Disease stage at the beginning of } \\
\text { L2 }^{\#}\end{array}$} \\
\hline Metastatic & $60(95.2 \%)$ & $273(94.8 \%)$ & 1.00 & $188(96.9 \%)$ & 85 (90.4\%) & 0.043 \\
\hline Locally advanced & $3(4.8 \%)$ & $15(5.2 \%)$ & & $6(3.1 \%)$ & $9(9.6 \%)$ & \\
\hline \multicolumn{7}{|l|}{ Metastatic sites } \\
\hline Liver $^{\#-\text { yes }}$ & $44(69.8 \%)$ & $172(59.7 \%)$ & 0.13 & $116(59.8 \%)$ & $56(59.6 \%)$ & 1.00 \\
\hline Lung $^{\#}$ - yes & $22(34.9 \%)$ & $80(27.8 \%)$ & 0.26 & $54(27.8 \%)$ & $26(27.7 \%)$ & 0.98 \\
\hline Bone $^{\#}-$ yes & $8(12.7 \%)$ & $26(9.0 \%)$ & 0.37 & $23(11.9 \%)$ & $3(3.2 \%)$ & 0.016 \\
\hline Lymph node ${ }^{\#}$ - yes & $20(31.7 \%)$ & $110(38.2 \%)$ & 0.34 & $84(43.3 \%)$ & $26(27.7 \%)$ & 0.010 \\
\hline Peritoneum $\#$ - yes & $24(38.1 \%)$ & $109(37.8 \%)$ & 0.97 & $76(39.2 \%)$ & $33(35.1 \%)$ & 0.50 \\
\hline $\begin{array}{l}\text { Total bilirubin - } \mu \mathrm{mol} / \mathrm{L} \text {, median } \\
\text { (IQR) }\end{array}$ & $15.0(9.5-17.0)$ & $11.0(6.0-17.0)$ & 0.028 & $11.0(6.0-17.0)$ & $12.0(6.9-17.0)$ & 0.20 \\
\hline Missing & 19 & $\begin{array}{c}11.0(0.0-11.0) \\
72\end{array}$ & $0.0<0$ & 50 & 22 & \\
\hline
\end{tabular}




\begin{tabular}{|c|c|c|c|c|c|c|}
\hline $\begin{array}{l}\text { Albumin - } \mathrm{g} / \mathrm{L}, \text { median (IQR) } \\
\quad \text { Missing }\end{array}$ & $\begin{array}{c}34.2(30.2-37.0) \\
37\end{array}$ & $\begin{array}{c}34.1(30.0-38.4) \\
171\end{array}$ & 0.53 & $\begin{array}{c}34.9(30.0-38.0) \\
115\end{array}$ & $\begin{array}{c}32.6(29.7-39.5) \\
56\end{array}$ & 0.99 \\
\hline $\begin{array}{l}\text { Serum CA19-9 - UI/mL, median } \\
\text { (IQR) }\end{array}$ & $319.5(52.9-5580)$ & $141.5(38.0-987.5)$ & 0.035 & $\begin{array}{c}141.5(36.0- \\
963.0)\end{array}$ & $\begin{array}{c}135.3(51.0- \\
1406.0)\end{array}$ & 0.48 \\
\hline Missing & 27 & 108 & & 72 & 36 & \\
\hline \multicolumn{7}{|l|}{ L3 chemotherapy } \\
\hline Yes & $20(32.8 \%)$ & $130(45.8 \%)$ & 0.063 & $81(42.2 \%)$ & 49 (53.3\%) & 0.098 \\
\hline Missing & 2 & 4 & & 2 & 2 & \\
\hline
\end{tabular}

\# No missing data

* Prior resection of the primary tumor was defined as surgery with R0/R1 resection and no evidence of disease within one month post-surgery

${ }^{* *}$ Duration of $\mathrm{L} 1$ was calculated from the date of first administration of $\mathrm{L} 1$ to the date of first administration of $\mathrm{L} 2$

CA19-9: carbohydrate antigen 19-9, CR: complete response, IQR: interquartile range, L1: first-line treatment, L2: second-line treatment, L3: third-line treatment, PD:

progressive disease, PR: partial response, PS: performance status, SD: stable disease 
Table 3. Patient characteristics in the Italian (GICO) cohort according to monotherapy, irinotecan-based or platinum-based combination regimen in second line.

\begin{tabular}{|c|c|c|c|c|c|c|}
\hline & $\begin{array}{l}\text { Fluoropyrimidine } \\
\text { monotherapy } \\
(n=98)\end{array}$ & $\begin{array}{c}\text { Fluoropyrimidine }+ \\
\text { irinotecan }(n=60) \text { or } \\
\text { Fluoropyrimidine + } \\
\text { platinum }(n=16) \\
(n=76)\end{array}$ & $p$-value & $\begin{array}{l}\text { Fluoropyrimidine + } \\
\text { irinotecan } \\
(n=60)\end{array}$ & $\begin{array}{l}\text { Fluoropyrimidine }+ \\
\text { platinum } \\
(n=16)\end{array}$ & $p$-value \\
\hline \multicolumn{7}{|l|}{ Sex $\#$} \\
\hline Male & $41(41.8 \%)$ & $46(60.5 \%)$ & 0.015 & $35(58.3 \%)$ & $11(68.8 \%)$ & 0.45 \\
\hline Age - years, median (IQR) & $66.2(59.5-71.8)$ & $63.3(55.3-69.2)$ & 0.029 & $62.5(54.9-69.4)$ & $63.6(58.3-68.8)$ & \multirow{2}{*}{0.82} \\
\hline Missing & 1 & 0 & & 0 & 0 & \\
\hline \multicolumn{7}{|l|}{ Primary tumor site ${ }^{\#}$} \\
\hline Intrahepatic & $62(63.3 \%)$ & $41(54.0 \%)$ & 0.43 & $35(58.3 \%)$ & $6(37.5 \%)$ & \multirow[t]{3}{*}{0.27} \\
\hline Extrahepatic/hilar & $19(19.4 \%)$ & $17(22.3 \%)$ & & $13(21.7 \%)$ & $4(25.0 \%)$ & \\
\hline Gallbladder & $17(17.4 \%)$ & $18(23.7 \%)$ & & $12(20.0 \%)$ & $6(37.5 \%)$ & \\
\hline \multicolumn{7}{|c|}{ Prior resection of primary tumor ${ }^{\#, *}$} \\
\hline Yes & $32(32.7 \%)$ & $19(25.0 \%)$ & 0.27 & $14(23.3 \%)$ & $5(31.3 \%)$ & 0.53 \\
\hline \multicolumn{7}{|l|}{ Radiotherapy\# } \\
\hline Yes & $7(7.1 \%)$ & $5(6.6 \%)$ & 0.88 & $4(6.7 \%)$ & $1(6.3 \%)$ & 1.00 \\
\hline \multicolumn{7}{|l|}{ Biliary drainage } \\
\hline Yes & $23(23.7 \%)$ & $19(25.0 \%)$ & 0.84 & $14(23.3 \%)$ & $5(31.3 \%)$ & 0.53 \\
\hline Missing & 1 & 0 & & 0 & 0 & \\
\hline \multicolumn{7}{|l|}{ Type of L1 regimen ${ }^{\#}$} \\
\hline Gemcitabine + oxaliplatin & $63(64.3 \%)$ & 30 (39.5\%) & 0.0011 & $26(43.3 \%)$ & $4(25.0 \%)$ & 0.25 \\
\hline Gemcitabine + cisplatin & $35(35.7 \%)$ & 46 (60.5\%) & & $34(56.7 \%)$ & $12(75.0 \%)$ & \\
\hline
\end{tabular}




\begin{tabular}{|c|c|c|c|c|c|c|}
\hline \multicolumn{7}{|l|}{ Best response to $\mathrm{L} 1$} \\
\hline$C R$ & $0(0 \%)$ & $1(1.3 \%)$ & 0.69 & $1(1.7 \%)$ & $0(0 \%)$ & 1.00 \\
\hline$P R / S D$ & $56(58.3 \%)$ & $43(56.6 \%)$ & & $34(56.7 \%)$ & $9(56.3 \%)$ & \\
\hline$P D$ & $40(41.7 \%)$ & $32(42.1 \%)$ & & $25(41.7 \%)$ & $7(43.8 \%)$ & \\
\hline Missing & 2 & 0 & & 0 & 0 & \\
\hline Duration of L1 - months ${ }^{* *}$ & $5.7(3.5-8.7)$ & $5.9(3.4-8.8)$ & 0.92 & $5.9(3.6-9.4)$ & $6.3(3.3-8.6)$ & 0.69 \\
\hline Missing & 1 & 1 & & 1 & 0 & \\
\hline \multicolumn{7}{|c|}{ Reason for L1 discontinuation } \\
\hline Toxicity & 4 (4.2\%) & 7 (9.3\%) & 0.13 & 4 (6.8\%) & 3 (18.8\%) & 0.019 \\
\hline Other & $24(25 \%)$ & $11(14.7 \%)$ & & $6(10.2 \%)$ & $5(31.2 \%)$ & \\
\hline$P D$ & $68(70.8 \%)$ & $57(76.0 \%)$ & & $49(83.1 \%)$ & $8(50.0 \%)$ & \\
\hline Missing & 2 & 1 & & 1 & 0 & \\
\hline \multicolumn{7}{|l|}{ PS at the beginning of L2 } \\
\hline 0 & $28(29.2 \%)$ & $24(31.6 \%)$ & 0.23 & $18(30.0 \%)$ & $6(37.5 \%)$ & 0.63 \\
\hline 1 & $44(45.8 \%)$ & $41(53.9 \%)$ & & $32(53.3 \%)$ & $9(56.3 \%)$ & \\
\hline 2 & $24(25.0 \%)$ & $11(14.4 \%)$ & & $10(16.7 \%)$ & $1(6.3 \%)$ & \\
\hline Missing & 2 & 0 & & 0 & 0 & \\
\hline \multicolumn{7}{|c|}{ Disease stage at the beginning of } \\
\hline $\mathbf{L} 2$ & 92 (94.9\%) & $75(98.7 \%)$ & 0.23 & & & \\
\hline Metastatic & $5(5.1 \%)$ & $1(1.3 \%)$ & & $\begin{array}{c}60(100 \%) \\
0(0 \%)\end{array}$ & $\begin{array}{c}15(93.8 \%) \\
1(6.2 \%)\end{array}$ & 0.21 \\
\hline Locally advanced & 1 & 0 & & $\begin{array}{c}0(0 \%) \\
0\end{array}$ & $\begin{array}{c}1(6.2 \%) \\
\cdot 0\end{array}$ & \\
\hline \multicolumn{7}{|l|}{ Metastatic sites } \\
\hline Liver" - yes & $62(63.3 \%)$ & $51(67.1 \%)$ & 0.60 & $41(68.3 \%)$ & $10(62.5 \%)$ & 0.77 \\
\hline Lung - yes & $29(29.9 \%)$ & $23(30.3 \%)$ & 0.96 & $19(31.7 \%)$ & $4(25.0 \%)$ & 0.76 \\
\hline Missing & 1 & 0 & & 0 & 0 & \\
\hline Bone-yes & $11(11.3 \%)$ & $7(9.3 \%)$ & 0.67 & $5(8.3 \%)$ & $2(13.3 \%)$ & 0.62 \\
\hline Missing & 1 & 1 & & 0 & 1 & \\
\hline Lymph node - yes & $52(53.6 \%)$ & $43(56.6 \%)$ & 0.70 & $33(55.0 \%)$ & $10(62.5 \%)$ & 0.78 \\
\hline
\end{tabular}




\begin{tabular}{|c|c|c|c|c|c|c|}
\hline Missing & 1 & 0 & & 0 & 0 & \\
\hline Peritoneum - yes & $25(25.8 \%)$ & $24(31.6 \%)$ & 0.40 & $18(30.0 \%)$ & $6(37.5 \%)$ & 0.57 \\
\hline Missing & 1 & 0 & & 0 & 0 & \\
\hline $\begin{array}{l}\text { Total bilirubin - } \mu \mathrm{mol} / \mathrm{L}, \text { median } \\
\text { (IQR) }\end{array}$ & $10.3(7.4-15.9)$ & $10.3(7.5-17.2)$ & 0.87 & $9.8(7.2-17.1)$ & $11.1(8.4-19.3)$ & 0.50 \\
\hline Missing & 22 & 12 & & 10 & 2 & \\
\hline Albumin - $\mathrm{g} / \mathrm{L}$, median (IQR) & $35.0(29.0-38.0)$ & $35.5(29.0-40.0)$ & 0.70 & $35.5(26.0-39.5)$ & $35.0(32.0-43.0)$ & 0.40 \\
\hline Missing & 39 & 34 & & 28 & 6 & \\
\hline $\begin{array}{l}\text { Serum CA19-9 - UI/mL, median } \\
\text { (IQR) }\end{array}$ & $95.5(30.1-614.0)$ & $292(64.45-1624.5)$ & 0.028 & $\begin{array}{c}156.2(48.7- \\
1272.0)\end{array}$ & $848.0(133.7-2430)$ & 0.11 \\
\hline Missing & 23 & 8 & & 6 & & \\
\hline \multicolumn{7}{|l|}{ L3 chemotherapy } \\
\hline Yes & $28(28.6 \%)$ & $18(23.7 \%)$ & 0.47 & $14(30.4 \%)$ & $4(25.0 \%)$ & 1.00 \\
\hline Missing & 0 & 0 & & 0 & 2 & \\
\hline
\end{tabular}

\# No missing data

* Prior resection of the primary tumor was defined as surgery with R0/R1 resection and no evidence of disease within one month post-surgery

${ }^{* *}$ Duration of $L 1$ was calculated from the date of first administration of $L 1$ to the date of first administration of $L 2$

CA19-9: carbohydrate antigen 19-9, CR: complete response, IQR: interquartile range, L1: first-line treatment, L2: second-line treatment, L3: third-line treatment, PD: progressive disease, PR: partial response, PS: performance status, SD: stable disease 


\section{FIGURE LEGENDS}

Figure 1. Kaplan-Meier curves of the overall survival estimation for patients treated with a combination or a monotherapy as second line treatment. French (AGEO CT2BIL) cohort: overall population (Hazard Ratio [HR]: $0.936,95 \% \mathrm{Cl}: 0.701$ to $1.250, p=0.6532$ ) (A), subgroup of patients with ECOG PS 0-1 (HR: 1.127, 95\%Cl: 0.750 to 1.694, $p=0.5654$ ) (B) and 2 (HR: 1.005, $95 \% \mathrm{Cl}: 0.637$ to $1.586, p=0.9816$ ) (C). Italian (GICO) cohort: overall population (HR: 0.782, 95\% Cl: 0.556 to 1.100, $p=0.1572$ ) (D), subgroup of patients with ECOG PS 0-1 (HR: 0.915, $95 \% \mathrm{Cl}: 0.623$ to $1.344, p=0.6521$ ) (E) and 2 (HR: $0.631,95 \% \mathrm{Cl}: 0.278$ to $1.435, p=0.2723$ ) (F).

Figure 2. Kaplan-Meier curves of the overall survival estimation for patients treated with a monotherapy or a combination with irinotecan or platinum second-line treatment. French (AGEO CT2BIL) cohort: overall population (Hazard Ratio [HR]: $0.879,95 \% \mathrm{Cl}: 0.629$ to 1.227 for platinum doublet vs. monotherapy and $\mathrm{HR}$ : $0.972,95 \% \mathrm{Cl}: 0.717$ to 1.319 for irinotecan doublet vs. monotherapy, $p=0.6846$ ) (A), subgroup of patients with PS 0-1 (HR: $1.007,95 \% \mathrm{Cl}$ : 0.636 to 1.595 for platinum doublet vs. monotherapy and HR: $1.202,95 \% \mathrm{Cl}: 0.788$ to 1.835 for irinotecan doublet vs. monotherapy, $p=0.4730$ ) (B) and 2 (HR: $1.089,95 \% \mathrm{Cl}: 0.615$ to 1.928 for platinum doublet vs. monotherapy and HR: $0.969,95 \% \mathrm{Cl}: 0.596$ to 1.576 for irinotecan doublet vs. monotherapy, $p=0.9048$ ) (C). Italian (GICO) cohort: overall population (HR: 1.140, 95\% Cl: 0.634 to 2.053 for platinum doublet vs. monotherapy and HR: $0.709,95 \% \mathrm{Cl}: 0.487$ to 1.031 for irinotecan doublet $v s$. monotherapy, $p=0.1439)(D)$, subgroup of patients with ECOG PS 0-1 (HR: $1.396,95 \% \mathrm{Cl}: 0.747$ to 2.610 for platinum doublet $v s$. monotherapy and HR: 0.814 , $95 \% \mathrm{Cl}: 0.533$ to 1.242 for irinotecan doublet $v s$. monotherapy, $p=0.2737$ ) (E) and 2 (HR: 1.021, 95\%Cl: 0.135 to 7.711 for platinum doublet vs. monotherapy and HR: $0.596,95 \% \mathrm{Cl}: 0.250$ to 1.418 for irinotecan doublet vs. monotherapy, $p=0.5005)(F)$. 
Advanced biliary tract carcinoma is usually diagnosed at an advanced stage, and requires firstline chemotherapy. For those patients who go on to second-line chemotherapy, most receive fluoropyrimidine (FP) alone or in combination. Here, the authors compared overall survival between patients given a second-line treatment of FP monotherapy versus those given FP plus either irinotecan or platinum. They stratified patients by therapy regimen and by ECOG performance status, which is considered the best prognostic factor for second-line treatment. They found that overall survival was comparable, whether patients received FP alone or in combination, even after controlling for performance status. 

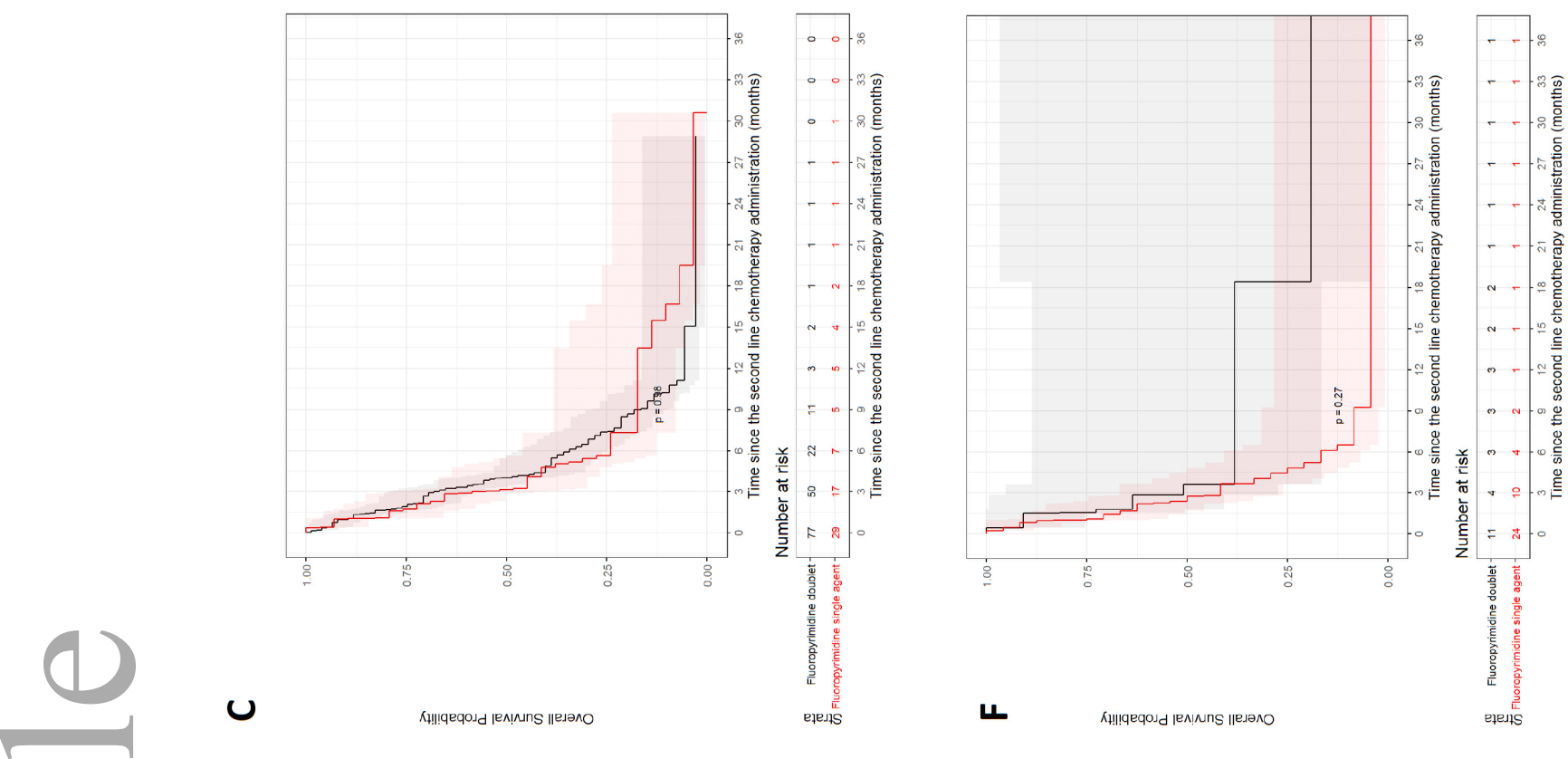

○
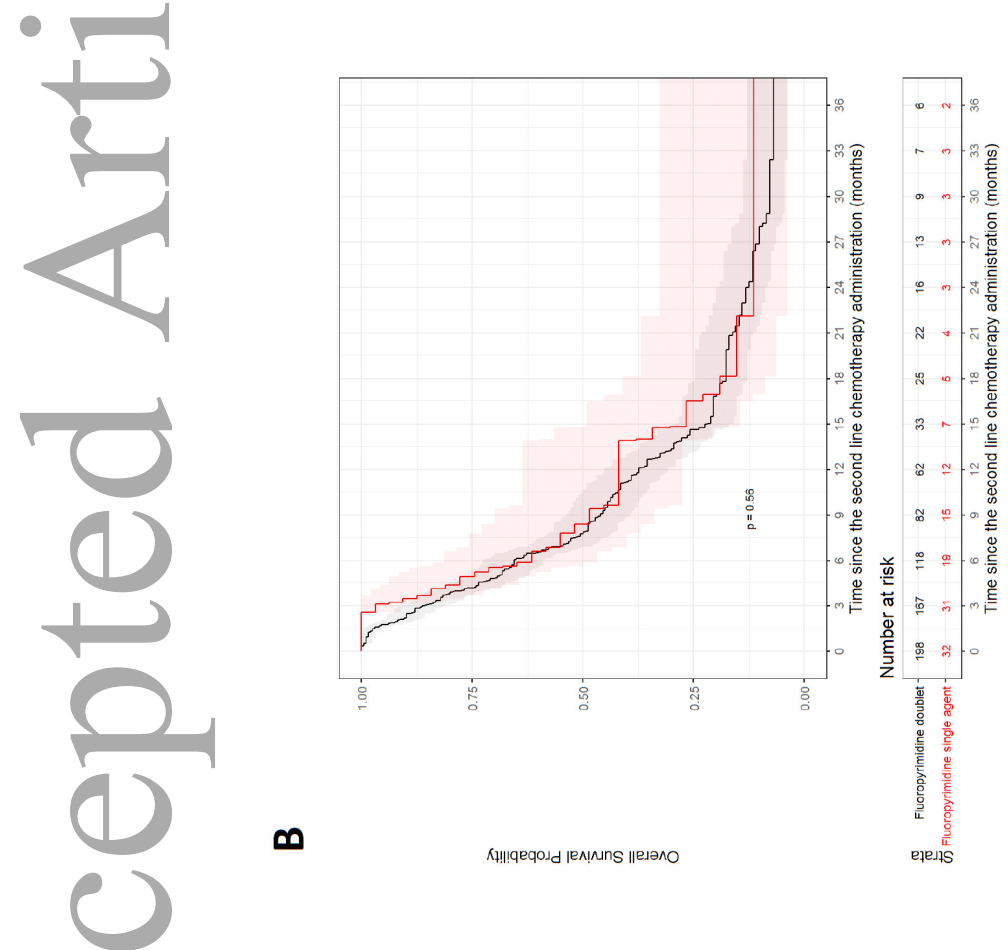

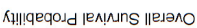
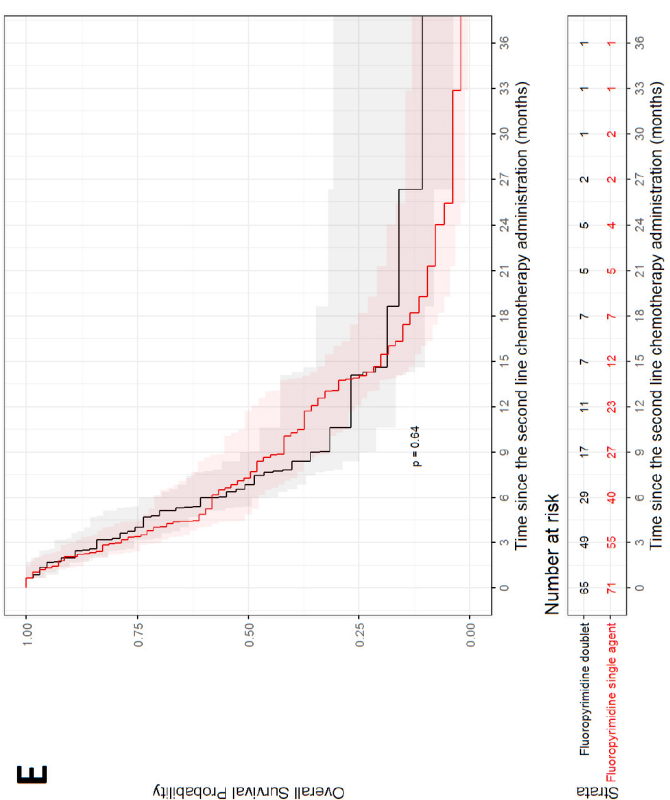

O
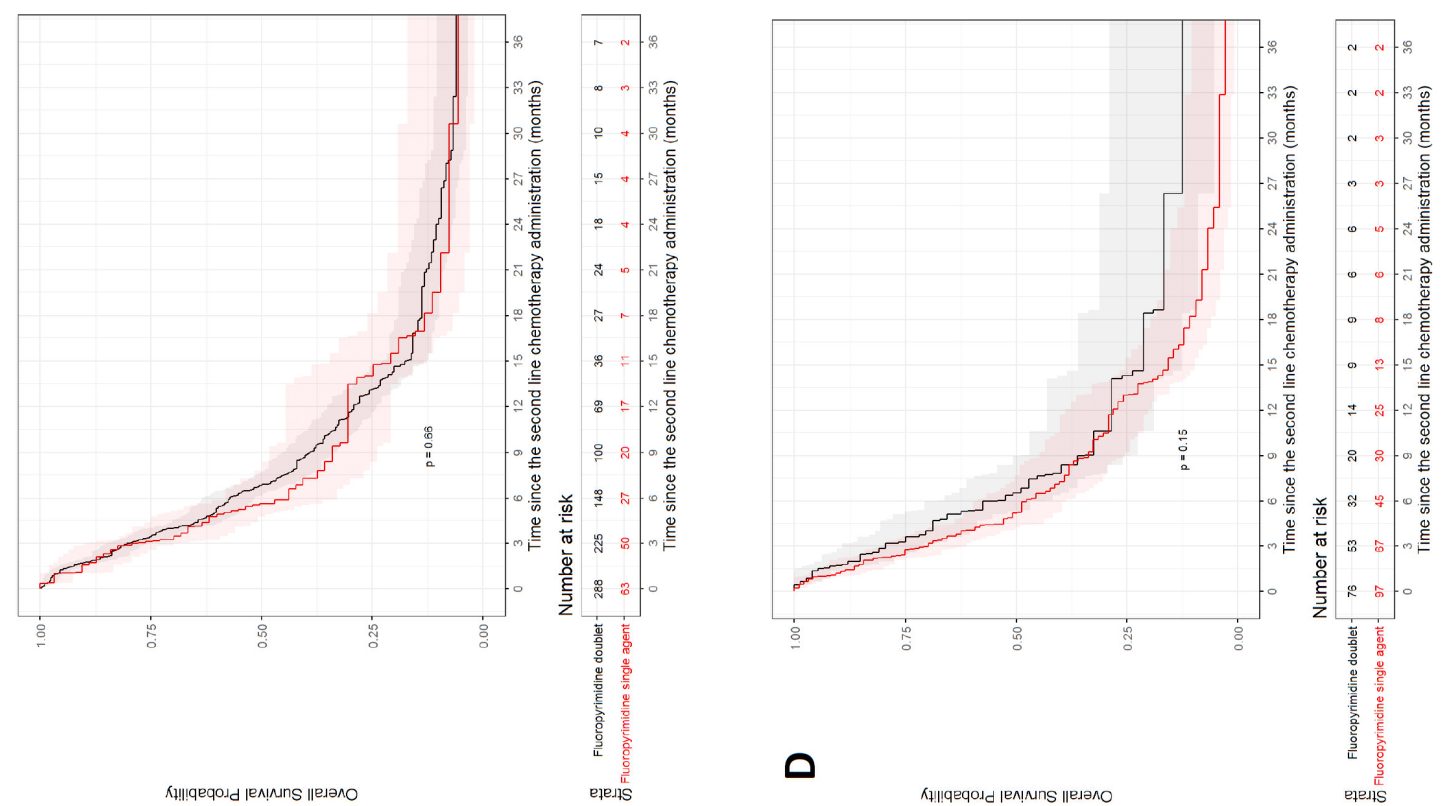


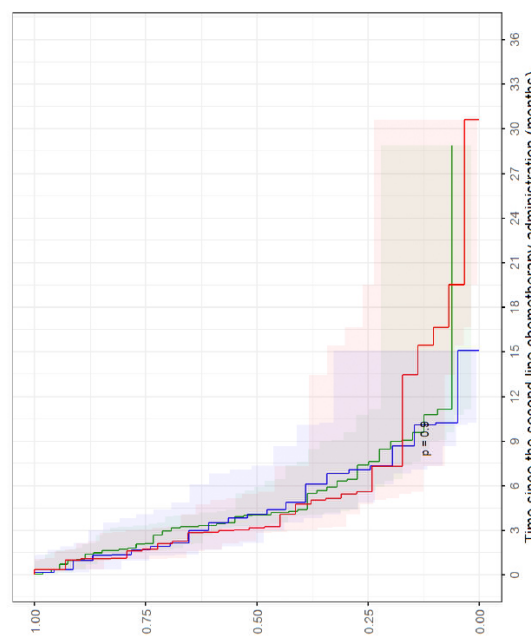

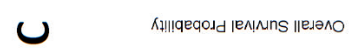

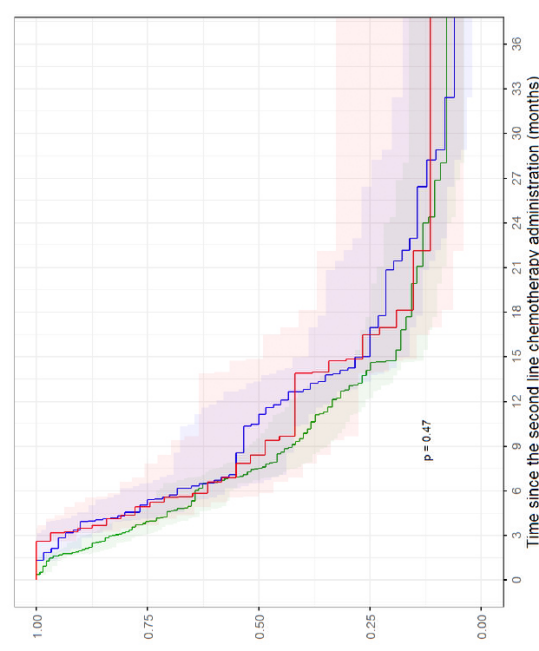

$\infty$

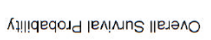
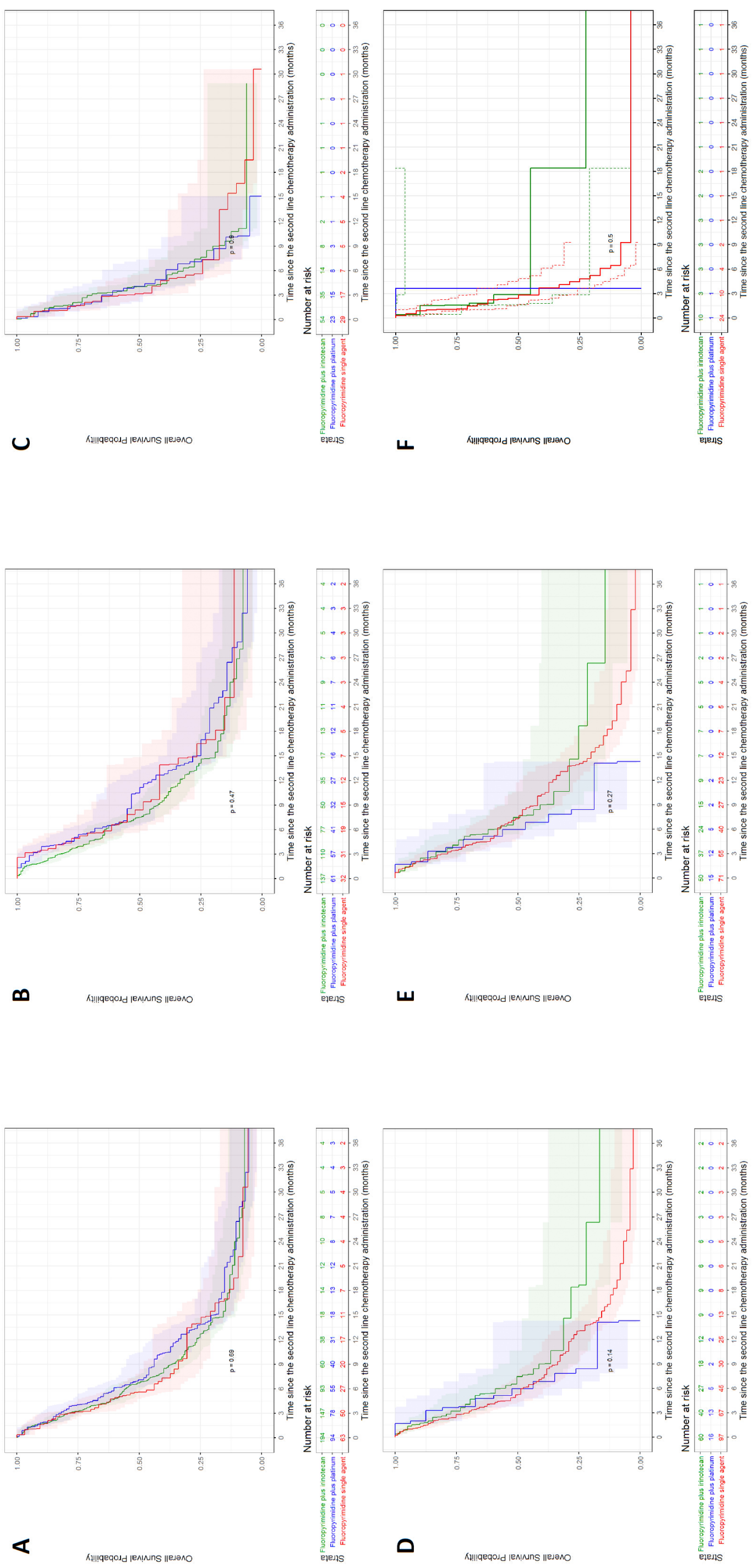